\title{
BMJ Open Funnel plots and choropleth maps in cancer risk communication: a comparison of tools for disseminating population-based incidence data to stakeholders
}

\author{
Walter Mazzucco, ${ }^{1,2}$ Rosanna Cusimano, ${ }^{1,3}$ Maurizio Zarcone, ${ }^{1,4}$ \\ Sergio Mazzola, ${ }^{1,4}$ Francesco Vitale ${ }^{1,2,4}$
}

To cite: Mazzucco W, Cusimano R, Zarcone M, et al. Funnel plots and choropleth maps in cancer risk communication: a comparison of tools for disseminating populationbased incidence data to stakeholders. BMJ Open 2017;7:e11502.

doi:10.1136/bmjopen-2016011502

- Prepublication history and additional material is available. To view please visit the journal (http://dx.doi.org/ 10.1136/bmjopen-2016011502)

Received 3 April 2016 Revised 28 October 2016 Accepted 22 December 2016

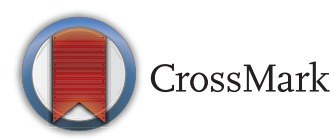

For numbered affiliations see end of article.

Correspondence to Dr Walter Mazzucco; walter.mazzucco@unipa.it

\section{ABSTRACT}

Background: Population-based cancer registries provide epidemiological cancer information, but the indicators are often too complex to be interpreted by local authorities and communities, due to numeracy and literacy limitations. The aim of this paper is to compare the commonly used visual formats to funnel plots to enable local public health authorities and communities to access valid and understandable cancer incidence data obtained at the municipal level.

Methods: A funnel plot representation of standardised incidence ratio (SIR) was generated for the 82 municipalities of the Palermo Province with the 20032011 data from the Palermo Province Cancer Registry (Sicily, Italy). The properties of the funnel plot and choropleth map methodologies were compared within the context of disseminating epidemiological data to stakeholders.

Results: The SIRs of all the municipalities remained within the control limits, except for Palermo city area $(\mathrm{SIR}=1.12)$, which was sited outside the upper control limit line of $99.8 \%$. The Palermo Province SIRs funnel plot representation was congruent with the choropleth map generated from the same data, but the former resulted more informative as shown by the comparisons of the weaknesses and strengths of the 2 visual formats.

Conclusions: Funnel plot should be used as a complementary valuable tool to communicate epidemiological data of cancer registries to communities and local authorities, visually conveying an efficient and simple way to interpret cancer incidence data.

\section{BACKGROUND}

Cancer is the second major cause of death in the developed countries. ${ }^{1}$ In the past few decades, the increasing burden of disease has caused major concerns in local communities, requiring local health authorities to

\section{Strengths and limitations of this study}

- To the best of our knowledge, this study explores for the first time the application of the funnel plot methodology to represent standardised cancer incidence ratio at the municipal level through a comparison with the commonly used visual format, as choropleth map.

- The results of this study support the use of funnel plot as a complement to choropleth map for disseminating epidemiological data of cancer registries to local communities and authorities.

- The proposed communication approach needs to be further validated in the field. To this end, the Palermo Province Cancer Registry has generated 82 municipal risk maps, one for each municipality of the province, and for a period of 1 year, qualified personnel from the registry will be involved in on-site meetings to share cancer incidence data with stakeholders (citizens, local authorities, general practitioners, specialised physicians, pharmacists, etc) using funnel plots. The Delphi consensus process will be explored as well by involving public health operators.

develop risk communication plans that address cancer incidence, survival and the potential impact of environmental exposure. ${ }^{2}$ Apart from the presumed effects of lifestyle changes and environmental factors on cancer trends, ${ }^{3-6}$ the global increase in cancer prevalence could be largely attributable to a combination of improved cancer survival $^{7}$ and ageing population. ${ }^{8}$ Local communities possess a variable degree of literacy and numeracy, which, in turn, influence their understanding of such demographical and epidemiological concepts. ${ }^{9}{ }^{10}$ Local public health and political authorities regularly engage in finding better ways to satisfy the growing demand for information on the 
impact of cancer by the general public. ${ }^{11}$ In particular, citizens often question if they live in an area at high risk for environmental exposure. ${ }^{2}$

The Centers for Diseases Control and Prevention (CDC) define public health surveillance as the "Ongoing, systematic collection, analysis, interpretation, and dissemination of data regarding a health-related event for use in public health action to reduce morbidity and mortality and to improve health." 12 Population-based cancer registries (PBCRs) carry out cancer surveillance by continuously collecting and classifying information on all new cancer cases within a defined population, and providing statistics on its occurrence for the purpose of assessing and controlling the impact of this disease on the community. ${ }^{13}$ The mission of PBCRs includes the translation and dissemination of evidences to enable informed decision-making and to empower the general population or other stakeholders, while preserving a rigorous methodological approach and facilitating a truthful interpretation of the data obtained. PBCR publications use validated and internationally shared measurements systems and employ terminology and visual formats that are easily understood by the scientific community, but often difficult to interpret for other stakeholders, particularly at the local level. ${ }^{14} 15$

The most commonly used format for reporting geographic comparisons of cancer epidemiological data is an atlas, which includes thematic maps, such as choropleth maps $(\mathrm{CMs})$, representing cancer incidence rates (standardised rates, standardised ratios, etc) computed for specific areas. ${ }^{16} 17$

While data are available on how the context ${ }^{18}$ and the content of such communications influence individual risk perception, ${ }^{19}$ little is known about the effects of risk communications at a group level, particularly in small communities. $^{20}$

The Italian Association of Cancer Registries (AIRTum), a national network of 41 local PBCRs, including the Palermo Province Cancer Registry (PPCR), has greatly emphasised improving communication tools. ${ }^{21}$

The aim of this paper is to propose the use of funnel plots (FPs) for reporting local cancer incidence data, as a complement to the more common visual formats employed by the PPCR to address local public health authorities and communities, in order to facilitate the dissemination and interpretation of measures of cancer statistics at the municipal level.

\section{METHODS}

The study population consists of the 51951 new cancer cases, excluding non-melanoma skin cancers, registered between 2003 and 2011 by the PPCR among the 1244239 residents of the 82 municipalities of the Palermo Province (PP; 679850 inhabitants within the Palermo metropolitan area only). ${ }^{22}$ Cancer incidence in the PP municipalities was measured by using standardised incidence ratio (SIR), defined as the ratio between observed cases $\left(\mathrm{O}_{\mathrm{i}}\right)$ and expected cases $\left(\mathrm{E}_{\mathrm{i}}\right) .^{23}$ The $\mathrm{O}_{\mathrm{i}}$ were assumed to follow a homogeneous Poisson distribution with parameter $\lambda=\theta_{0} \cdot \mathrm{E}_{\mathrm{i}}$. The $\mathrm{E}_{\mathrm{i}}$ were estimated by indirect method, ${ }^{24}$ considering the entire population time under study (the $\mathrm{PP}$ ) as the reference population, with $\Sigma \mathrm{O}_{\mathrm{i}}=\Sigma \mathrm{E}_{\mathrm{i}} \cdot{ }^{25}$ The resident population was reported using the intercensus estimates, provided by the Italian National Statistical Institute (ISTAT), also considering the annual municipal data on migration. ${ }^{22}$ For each SIR, the $95 \%$ CI was calculated by using the normal approximation method. ${ }^{26}$

Graphic FP representation ${ }^{26}$ was used to highlight any municipality with a higher cancer incidence compared with the reference population (entire PP population). The following elements were included to generate the FP (figure 1A): the SIRs of the 82 municipalities, on the $y$-axis; the target line $\left(\theta_{0}=1\right)$, representing the reference value for the indicator of interest $\left(\mathrm{O}_{\mathrm{i}}=\mathrm{E}_{\mathrm{i}}\right)$; the $\mathrm{E}_{\mathrm{i}}$ precision parameter, measuring the accuracy of the indicator of interest (Poisson variance parameter, using the hypothesis $\theta 0=1$ ), represented on the x-axis; the $95 \%$ and $99.8 \%$ CIs, calculated with the normal approximation method, defining the control limits. ${ }^{26}$ The two sets of control limit lines define three different areas within the graph (figure 1B): the 'undercontrol' area (in green), the 'warning' area (in yellow) and the 'alert' area (in red). ${ }^{27}$

As the data distribution was not congruent with the underlying assumption (variance equal to the expected value), in order to check for any potential overdispersion ${ }^{28}$ both additive and multiplicative approaches were adopted. Overdispersion coefficients ( $\tau$ for the additive approach and $\phi$ for the multiplicative approach) were calculated. Overdispersion was addressed by considering the winsorised estimates too. ${ }^{27}$ Moreover, Z-score ${ }^{29}$ and the winsorisation method (by testing for different levels of Z-score quantiles $^{28}$ ) were applied for the direct selection of extreme values. Furthermore, to define the level of winsorisation, an R-script routine was developed to set a cut-off for the quantile between the acceptance and rejection of the overdispersion test (see online supplementary material).

The map representing the PP municipalities was generated by using the ISTAT Shapefile vector format, ${ }^{30}$ released in the ED50 (European Datum - 1950) UTM Zone $32 \mathrm{~N}$ reference system, and converted in plane coordinates (decimal degrees), providing georeferenced data in addition to the coordinates of geographic objects and their borders (for polygons), also including the information on the location of each municipality. Although traditional geographical analyses use the centroids as geostatistical units, considering that some centroid could fall outside the municipal bounds, the coordinates of the city hall were used instead. ${ }^{31}$

The PP cancer incidence variation was also shown in a $\mathrm{CM}^{32}{ }^{32}$ representing the SIRs of each municipality. To distinguish potential high-risk and low-risk areas, a central interval of 0.95-1.05 for the colour scale was fixed, irrespective of statistical significance. Values above 1.05 and below 0.95 were divided in tertiles. ${ }^{33}$ 

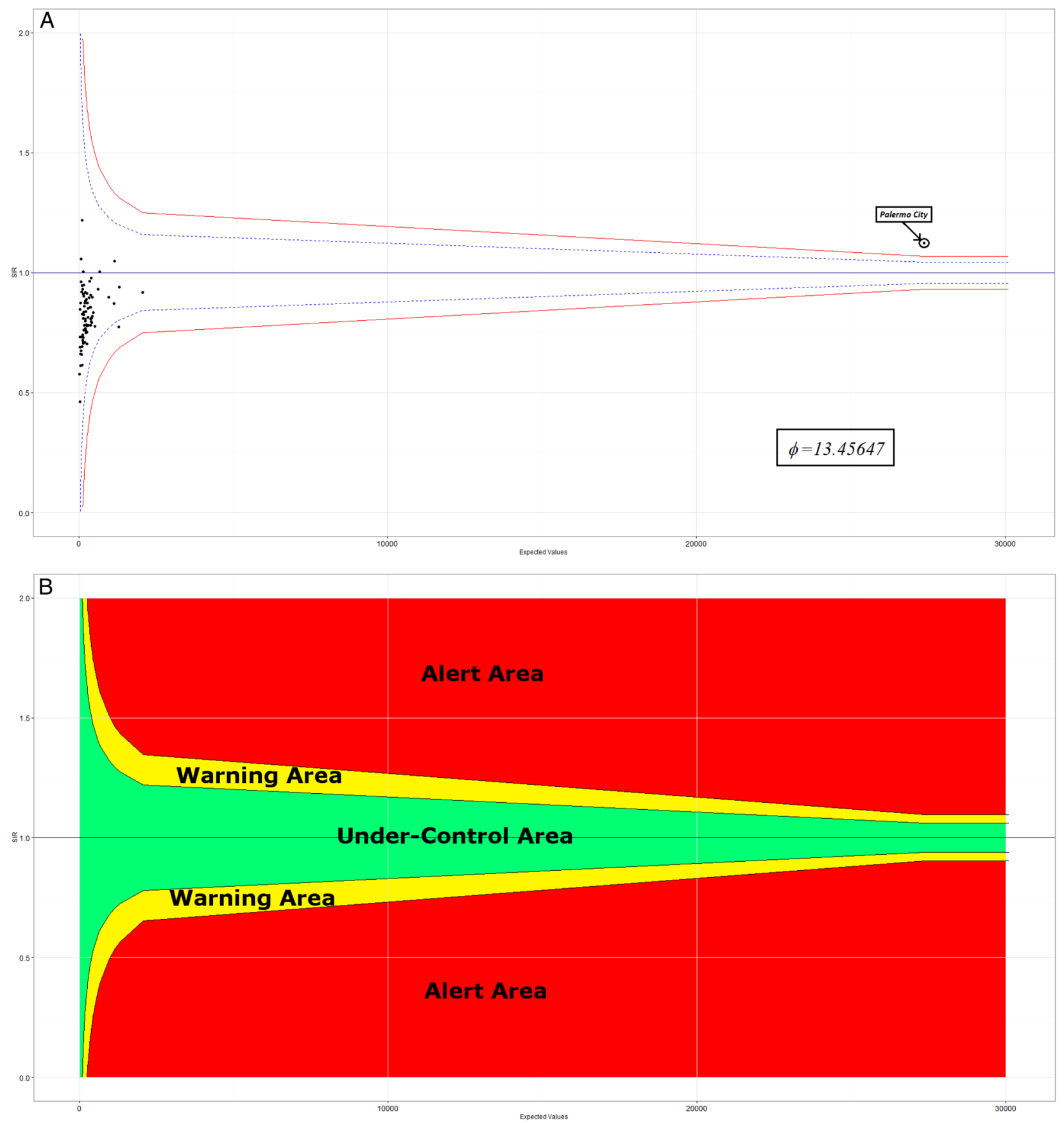

Figure 1 (A) Funnel plot of the SIRs in the 82 Palermo Province municipalities (study period 2003-2011); (B) cancer attention areas: 'undercontrol' area (in green), 'warning' area (in yellow) and 'alert' area (in red). Ninety-five per cent Cls ('blue' control lines) and $99.8 \% \mathrm{Cls}$ ('red' control lines); $\phi=$ overdispersion, calculated with multiplicative approach. SIR, standardised incidence ratio.

Cluster analysis was performed by using the scan statistics obtained with Openshaw's Geographical Analysis Machine (GAM), with varying radiuses, in order to detect potentials high-risk clusters and hot spot locations, setting the $p$ value at $0.002 .{ }^{34}$ The analysis for hot spot research was performed using circles with a $3 \mathrm{~km}$ radius for each point of a grid, covering the study region by steps of $600 \mathrm{~m}$ (radius/5). The RStudio IDE (RStudio Team. RStudio: Integrated Development for R. 2015. http://www.rstudio.com/ (accessed 18 Jan 2016)) for the R software, V.3.1.0 (2014-04-10)-'Spring Dance' (R Core Team. R: A language and environment for statistical computing 2015. http://www.R-project.org/ (accessed 18 Jan 2016)), was used to perform statistical analysis.

Finally, the weaknesses and strengths of the FP and CM methodological approaches were compared using the available literature as reference. ${ }^{29} 333536$ 


\section{RESULTS}

Figure 1A represents the FP of 82 municipality-specific SIRs, corrected for overdispersion $(\phi=13.46)$ and adjusted using the multiplicative approach. ${ }^{28}$ All of the SIRs lay within the control limits, except for the Palermo city 1 ( $\mathrm{SIR}=1.12)$, which resulted above the upper control limit line of $99.8 \%$. Figure 1B identifies the three different cancer risk areas within the graph.

Overdispersion test results were concordant and the routine did not find out any valid value for winsorisation (see online supplementary material, section B).

Figure 2 displays the $\mathrm{CM}$ for cancer incidence in the 82 PP municipalities, generated by using the SIRs. The map highlights three different municipality areas (ISTAT code: 082042 , 082053 and 082061 ; see table 1) with SIRs higher than 1.05 .

Table 1 represents the expected cases (both men and women) and SIRs with 95\% CIs in the 82 PP municipalities: most of the SIRs are lower than 1 and only six municipalities present SIRs higher than 1. Among them only Palermo had a statistically significant value higher than 1 (SIR=1, 12; 95\% CIs 1.11 to 1.14 ) while Isnello, the municipality showing the highest SIR, failed to meet the conventional criteria for statistical significance ( $\mathrm{SIR}=1.22 ; 95 \%$ CI 0.99 to 1.45 ).

No clusters were identified by the GAM approach, while a hot spot corresponding to Palermo city was highlighted (figure 3).

Table 2 summarises a comparison of the weaknesses and strengths, as per the available literature, ${ }^{29} 333536$ between the different visual formats explored within the context of disseminating epidemiological data to stakeholders.

As shown in the table 2, in terms of strengths, FP differed from $\mathrm{CM}$ in its ability to disseminate epidemiological data to stakeholders, in particular in the capability to show the scope of the phenomenon under investigation and the precision of estimates, and to highlight the significance of the estimates. On the other hand, CM, unlike FP, was able to define the spatial location of the risk and to locate the presence of any cluster. Both FP and CM were able to identify hot spots.

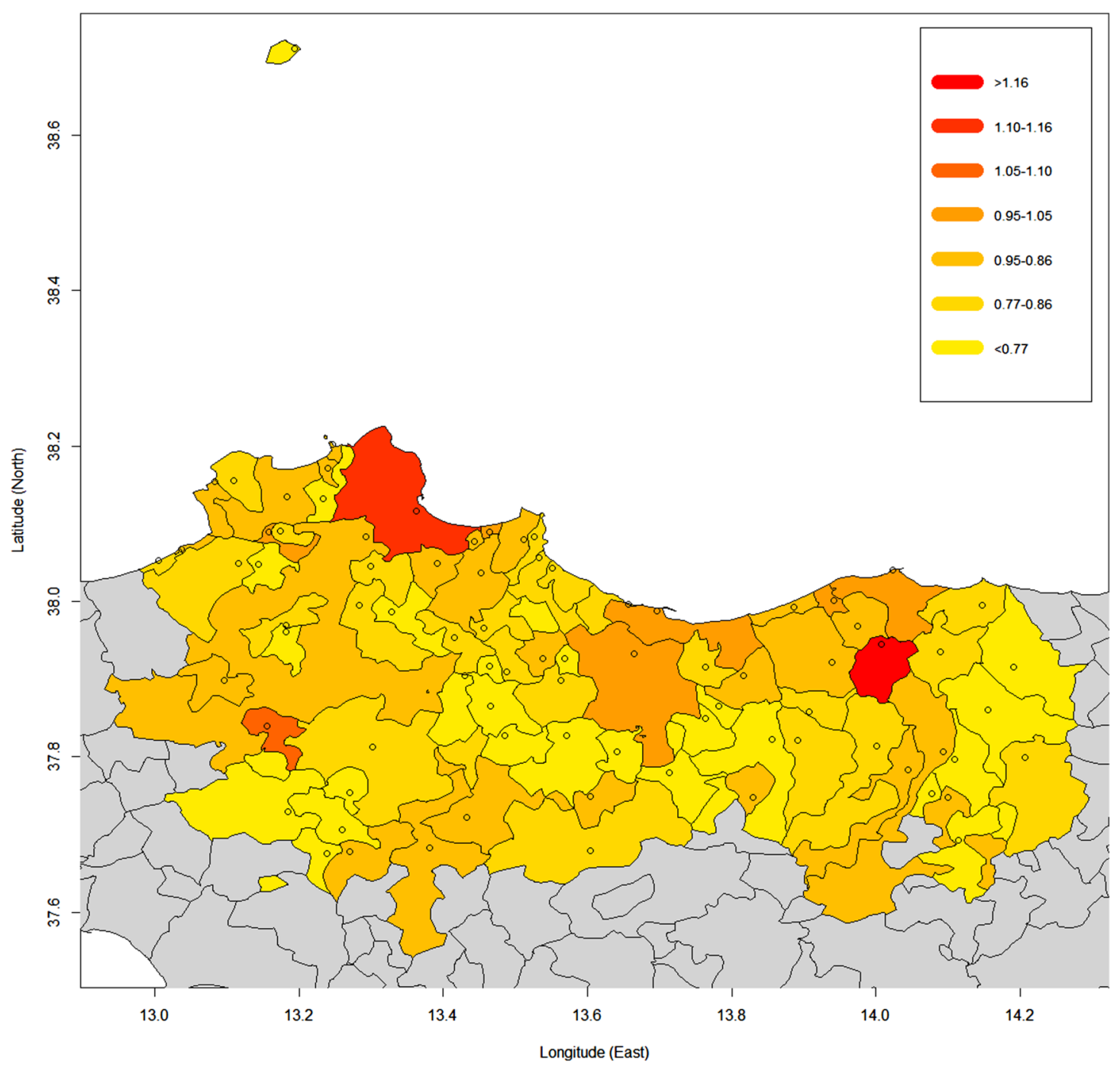

Figure 2 Choropleth map of the SIRs in the 82 Palermo Province municipalities^ (study period 2003-2011). ^Circles represent the locations of city halls. SIR, standardised incidence ratio. 
Table 1 Expected cases and SIRs (shown in a descending order) with $95 \%$ Cls in the $82 \mathrm{PP}$ municipalities (study period: 2003-2011, reference: the entire PP population)

\begin{tabular}{|c|c|c|c|c|c|c|c|c|c|}
\hline $\begin{array}{l}\text { ISTAT } \\
\text { code }\end{array}$ & Municipality & Expected & SIR & $95 \% \mathrm{Cl}$ & $\begin{array}{l}\text { ISTAT } \\
\text { code }\end{array}$ & Municipality & Expected & SIR & $95 \% \mathrm{Cl}$ \\
\hline 082042 & Isnello & 104.1 & 1.22 & 0.99 to 1.45 & 082031 & Cinisi & 441.0 & 0.82 & 0.74 to 0.90 \\
\hline 082053 & Palermo City & 27371.4 & 1.12 & 1.11 to 1.14 & 082007 & Balestrate & 292.4 & 0.81 & 0.72 to 0.91 \\
\hline 082061 & Roccamena & 81.4 & 1.06 & 0.83 to 1.29 & 082067 & Santa Flavia & 414.6 & 0.81 & 0.73 to 0.89 \\
\hline 082070 & Termini Imerese & 1166.4 & 1.05 & 0.99 to 1.11 & 082059 & Pollina & 148.0 & 0.81 & 0.68 to 0.94 \\
\hline 082027 & Cefalù & 685.3 & 1.01 & 0.93 to 1.08 & 082030 & Ciminna & 209.5 & 0.81 & 0.70 to 0.92 \\
\hline 082044 & Lascari & 152.2 & 1.01 & 0.85 to 1.17 & 082064 & San Giuseppe Jato & 379.0 & 0.81 & 0.73 to 0.89 \\
\hline 082014 & Caccamo & 396.1 & 0.98 & 0.88 to 1.07 & 082058 & Polizzi Generosa & 212.6 & 0.80 & 0.69 to 0.91 \\
\hline 082035 & Ficarazzi & 357.5 & 0.97 & 0.87 to 1.07 & 082036 & Gangi & 406.6 & 0.80 & 0.72 to 0.87 \\
\hline 082038 & Giardinello & 84.1 & 0.96 & 0.76 to 1.17 & 082023 & Casteldaccia & 416.4 & 0.79 & 0.72 to 0.89 \\
\hline 082056 & Petralia Sottana & 168.6 & 0.95 & 0.81 to 1.09 & 082004 & Altavilla Milicia & 242.8 & 0.78 & 0.68 to 0.88 \\
\hline 082012 & Bomp & 104.6 & 0.95 & 0.77 to 1.13 & 082005 & Altofo & 379.8 & 0.78 & o 0.86 \\
\hline 082049 & Monreale & 1319.0 & 0.94 & 0.89 to 0.99 & 082046 & Marin & 310.8 & 0.78 & 0.70 to 0.87 \\
\hline 082052 & Palazzo Adriano & 123.4 & 0.93 & 0.77 to 1.10 & 082025 & Castronovo di Sicilia & 175.4 & 0.78 & 0.67 to 0.90 \\
\hline 082079 & Villabate & 631.9 & 0.93 & 0.85 to 1.00 & 082050 & Montelepre & 258.1 & 0.78 & 0.68 to 0.87 \\
\hline 082008 & Baucina & 102.0 & 0.92 & 0.74 to 1.10 & 082034 & & & 0.78 & 0.71 to 0.84 \\
\hline 082006 & & 2068.7 & 0.92 & 0.88 to 0.96 & 082054 & & 1291.1 & 0.78 & o 0.82 \\
\hline 082076 & Valledolmo & 212.5 & 0.92 & 0.79 to 1.04 & 082051 & $\begin{array}{l}\text { Montemaggiore } \\
\text { Belsito }\end{array}$ & & 0.77 & 0.66 to 0.87 \\
\hline 082017 & $\begin{array}{l}\text { Campofelice di } \\
\text { Roccella }\end{array}$ & 272.6 & 0.91 & 0.80 to 1.02 & 082078 & Vicari & 156.2 & 0.76 & 0.64 to 0.88 \\
\hline 082074 & & 151.5 & 0.91 & .06 & 082001 & Al & 225.4 & 0.76 & o 0.86 \\
\hline 082020 & Capaci & 390.4 & 0.92 & 0.82 to 0.99 & 082010 & acquino & 272.7 & 0.75 & 0.66 to 0.84 \\
\hline 082019 & Cam & 157.5 & 0.90 & 0.76 to 1.04 & 0820 & & & 0.75 & 0.65 to 0.85 \\
\hline 082071 & Terra & 446.0 & 0.90 & $0.86 t$ & 082002 & Alim & 134.9 & 0.74 & o 0.87 \\
\hline 082048 & Misilmeri & 969.4 & 0.90 & 0.84 to 0.95 & 082065 & $\begin{array}{l}\text { San Mauro } \\
\text { Castelverde }\end{array}$ & 120.1 & 0.74 & 0.61 to 0.87 \\
\hline 082045 & Lercara Friddi & 335.8 & 0.90 & 0.80 to 0.99 & 082082 & Blufi & 76.5 & 0.73 & 0.57 to 0.90 \\
\hline 082028 & Cerda & 243.1 & 0.89 & & 003 & Alit & 73.8 & 0.73 & 0.57 to 0.90 \\
\hline 082043 & $\begin{array}{l}\text { Isola delle } \\
\text { Femmine }\end{array}$ & 235.3 & 0.88 & 0.77 to 0.99 & 082026 & Cefalà Diana & 50.6 & 0.73 & 0.53 to 0.93 \\
\hline 082032 & Collesano & 220.9 & 0.88 & 0.77 to 0.99 & 082072 & & 143.6 & 0.73 & 0.61 to 0.85 \\
\hline 082024 & $\begin{array}{l}\text { Castellana } \\
\text { Sicula }\end{array}$ & 200.3 & 0.87 & 0.75 to 0.99 & 082039 & Giuliana & 121.2 & 0.72 & 0.59 to 0.85 \\
\hline 082041 & Gratteri & & 0.87 & 0.66 to 1.09 & 082047 & & 146.5 & 0.71 & 0.60 to 0.82 \\
\hline 082060 & Prizzi & 283.8 & 0.87 & 0.77 to 0.98 & 082055 & Soprana & 201.3 & 0.71 & 0.61 to 0.81 \\
\hline 082021 & Carini & 1146.5 & 0.87 & & & & 139.0 & 0.71 & 0.59 to 0.82 \\
\hline 082029 & Chiusa & & 0.86 & & 082013 & & 261.3 & 0.70 & 0.62 to 0.79 \\
\hline 082009 & $\begin{array}{l}\text { Belmonte } \\
\text { Mezzagno }\end{array}$ & 372.3 & 0.86 & 0.77 to 0.94 & 082037 & Geraci Siculo & 112.7 & 0.69 & 0.56 to 0.82 \\
\hline 082073 & Trabia & & 0.86 & & & & 40.6 & 0.69 & 0.48 to 0.90 \\
\hline 082057 & $\begin{array}{l}\text { Piana degli } \\
\text { Albanesi }\end{array}$ & 305.0 & 0.85 & 0.76 to 0.95 & 082018 & Campofiorito & 74.2 & 0.67 & 0.52 to 0.83 \\
\hline 082081 & Scillato & & 0.85 & 0.57 to 1. & & & 66.6 & 0.66 & 0.50 to 0.82 \\
\hline 082015 & Caltavuturo & 229.0 & 0.84 & 0.73 to 0.95 & 082033 & Conte & 101.6 & 0.66 & 0.53 to 0.79 \\
\hline 082080 & Villafrati & & 0.84 & 0.71 to 0.96 & 082077 & niglia di Sicilia & 116.9 & 0.62 & 0.50 to 0.73 \\
\hline 082022 & Caste & & 0.83 & 0.76 to 0.91 & 082040 & no & 52.2 & 0.61 & 0.45 to 0.78 \\
\hline 082068 & Sciara & 117.2 & 0.83 & 0.68 to 0.98 & 082069 & Sclafani Bagni & 29.4 & 0.58 & 0.37 to 0.79 \\
\hline 082011 & Bolognetta & 162.6 & 0.82 & 0.70 to 0.95 & 082016 & $\begin{array}{l}\text { Campofelice di } \\
\text { Fitalia }\end{array}$ & 34.6 & 0.46 & 0.31 to 0.62 \\
\hline
\end{tabular}

Bold typeface indicates a significant SIR value.

ISTAT, Italian National Statistical Institute; SIR, standardised incidence ratio; PP, Palermo Province.

\section{DISCUSSION}

FPs are commonly used in process control and, in particular, in the healthcare field to compare institutional performance data; ${ }^{29}$ however, this format is used for survival $^{37}$ and standardised mortality ratio $^{29}$ in public health surveillance. ${ }^{38}$ We explored the use of FPs as a supplementary tool to local provide authorities and communities with synthetic access to valid and 


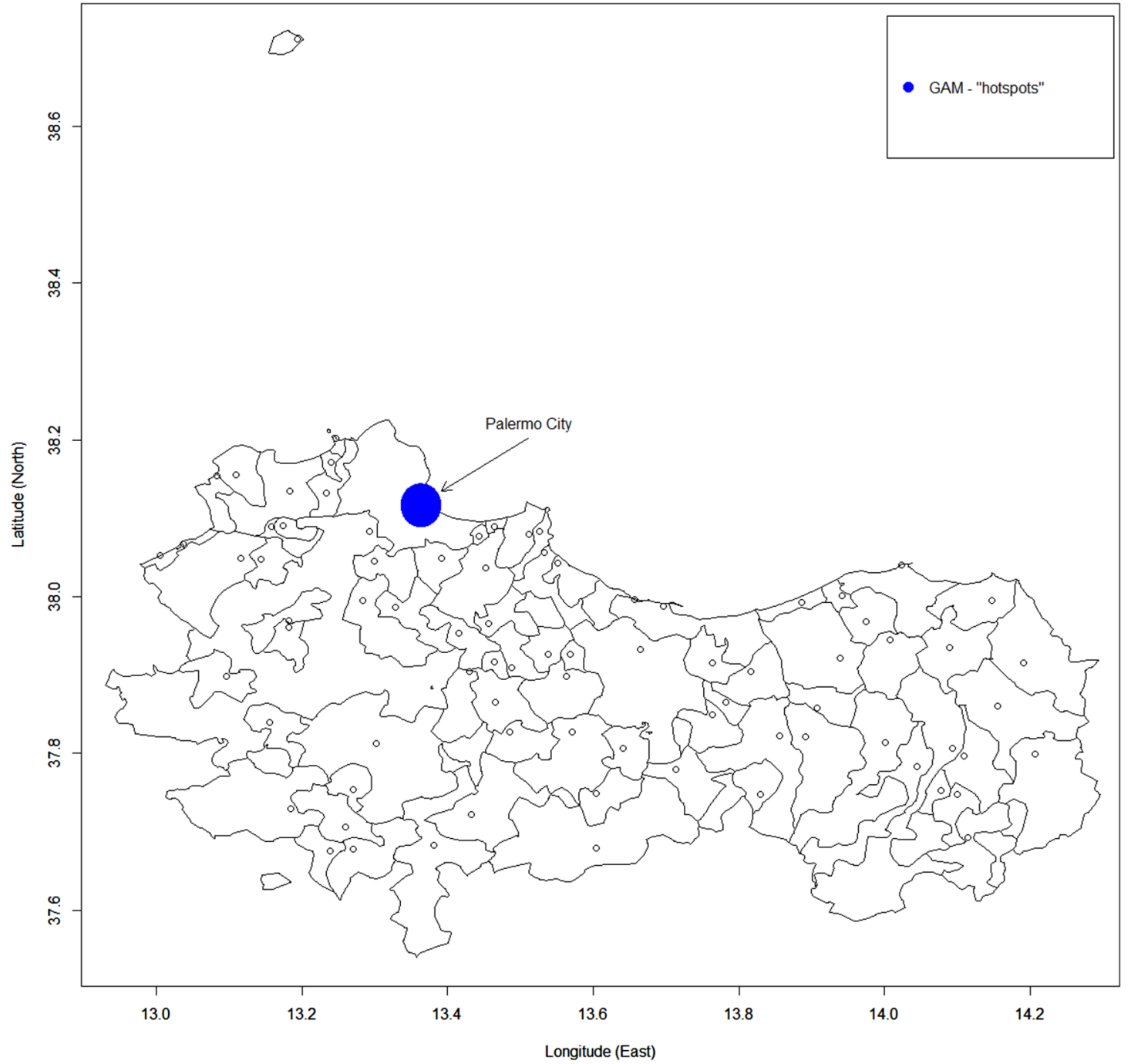

Figure 3 GAM map of the Palermo Province (study period 2003-2011). GAM, Geographical Analysis Machine; SIR, standardised incidence ratio.

Table 2 Comparison of the weaknesses (-) and strengths $(+)$ of the funnel plot and choropleth map within the context of disseminating epidemiological data to stakeholders

\begin{tabular}{llr}
\hline & \multicolumn{2}{c}{ Weaknesses and strengths of visual format } \\
\cline { 2 - 2 } Properties explored & Funnel plot & Choropleth map \\
\hline Definition of the spatial location of the risk & - & + \\
Identification of hot spots & + & + \\
Locating clusters & + & + \\
Displaying the scope of the phenomenon under investigation & + \\
Showing the precision of estimates & + & - \\
Communicating the significance of estimates & + \\
\hline
\end{tabular}

understandable cancer incidence data (SIRs) obtained at the municipal level.

Given that SIR is an effective and well-established measure in the descriptive cancer epidemiology, ${ }^{23}$ we used this parameter to compare the use of FPs and the more common formats for reporting cancer epidemiological data.

Whereas scale-risk tables are easy to understand, ${ }^{19}$ readers do not usually take notice of the CI, which is a critically important measure of the precision of SIR estimates. ${ }^{39}$ By displaying sample statistics together with the corresponding sample size, in relation to the control limits, FPs allow visualising both information and precision levels without the need for processing several numeric values (in this study, we used 82 point estimates and 164 confidence boundaries). ${ }^{38}$ Moreover, while it is common knowledge that the numeracy skills of the general public are limited, that this obviously reduces 
the general understanding of public health statistics, studies have also documented that understanding of the CIs is poor even among physicians, as heuristic reasoning often prevails on sample size. ${ }^{40}$ Therefore, in order to facilitate comprehension of the epidemiological message, we have chosen the FP as a visual display method to allow the reader to identify the SIR for each municipality within the plot, and the different attentionlevel areas (represented by different colours) under which each location falls (figure 1B).

Reading a CM may be misleading for stakeholders ${ }^{41}$ since the fear of being overexposed to environmental and other risk factors may lead to misinterpretation of the differences in colour scale, which do not properly display the potential inaccuracy in the estimation of cancer indicators (figure 2). On the other hand, the conservative choice of reporting only statistically significant increased cancer risks, as shown for the Palermo city hot spot (figure 3), excludes from the discussion the residents of most municipalities who would certainly be interested in knowing 'what is going on in their back yard'. The combination of FP and CM, supported by tabulation of the numeric results, allows to identify locations where cancer incidence may deserve further attention, such as the municipality of Isnello, with a high SIR but a 95\% CI including the null value. Clear understanding by the relevant stakeholders and their productive engagement may clarify whether such borderline findings simply reflect inadequate sample size, chance or a departure from the expected incidence that deserves further investigation.

Within the context of the chosen sample population and data, it has to be considered the presence of a single area containing a large proportion of the entire study population must be highlighted. This obviously influences each SIR value, but its potential effects are related to the study population used in the calculation of SIRs, and do not influence the FP methodology itself. Moreover, the graphic FP representation, differently from the more commonly used visual formats, allows the reader to observe, simultaneously, the situation of the municipality of interest in relation to the entire study population and to three specific areas (under control, warning and alert) representing the different attention levels. Moreover, it should also be kept in mind that the SIR values have been standardised using the EU population as external reference, allowing adjustment for age. Finally, the presence of a single area with a substantial population (Palermo city) implies an overestimation of expected cases, but the epidemiological message did not change even after the exclusion of the Palermo city area from the analysis (data not shown).

Following the methodological approach proposed, representation of the PP SIRs through FP seemed to be congruent with $\mathrm{CM}$ generated using the same data, with the former resulting more informative dealing with some of the dimensions explored, as shown by the comparisons of the weaknesses and strengths between the two visual formats (table 2). In particular, with regard to the strengths of the proposed visual format, FP shows the scope of the phenomenon under investigation and the precision and significance of estimates simultaneously, by simply positioning the indicator of interest in one of the three cancer attention areas; ${ }^{29}$ on the contrary, the more commonly used CMs monodimensionally represent the parameters of interest by using a different colour gradation based on the frequency distribution of the values. $^{33} 3536$ The highlighted difference could be considered the main reason for making FP more comprehensive to stakeholders than CM. However, the weaknesses of FP also need to be taken into account. FP cannot be considered the ideal visual format to highlight the geographical position of the indicator of interest (SIR) and, consequently, to define any spatial cluster. ${ }^{29}$ Finally, both FP and CM had the ability to identify potential hot spots, even though for CM, it is necessary to further validate the hot spot by using suitable statistical tests (eg, the GAM approach). ${ }^{34}$ All of the previous considerations have led us to believe that FP could be used as a complement to $\mathrm{CM}$, according to its properties, particularly in terms of validity and in terms of interpretability.

However, the proposed complementary dissemination approach needs to be further validated in the field both by involving local communities and by administering the two different visual formats to a sample of stakeholders according to the Delphi consensus process. ${ }^{42}$ In fact, it can be presumed that the efficacy of a presentation format depends both on the type of format, and on the context in which the format is used (scientific vs general public). ${ }^{18}$

\section{CONCLUSIONS}

According to the proposed comparison between the two explored methodological approaches, we concluded that FP should be considered as a complement to the current and commonly used graphical and visual formats (CMs, tables, GAM maps) to effectively communicate cancer registry statistics, particularly incidence rate, to communities and local authorities, visually conveying an efficient and simple to interpret cancer epidemiological data.

Future research on cancer risk communication should concentrate on the presentation format and on the framework in which the message is presented. From this perspective, the FP could represent a useful tool for empowering health communications to local communities and other stakeholders (patients' associations, physicians, pharmacists, local administration, etc).

\section{Author affiliations}

${ }^{1}$ Registro Tumori di Palermo e Provincia, University of Palermo, Palermo, Italy ${ }^{2}$ Dipartimento Scienze Promozione della Salute e Materno Infantile "G. D’Alessandro", Sezione di Igiene, University of Palermo, Palermo, Italy ${ }^{3}$ Azienda Sanitaria Provinciale 6 di Palermo—Dipartimento di Prevenzione, Palermo, Italy

${ }^{4}$ Unità Operativa Complessa di Epidemiologia Clinica con Registro Tumori, Azienda Ospedaliera Universitaria Policlinico "Paolo Giaccone", Palermo, Italy 
Contributors All individuals listed as authors have contributed substantially to designing, performing or reporting of the study and every specific contribution is indicated as follows. WM, RC, MZ and SM were involved in conception and design of the study. MZ and SM were involved in statistical analysis. WM, RC $\mathrm{MZ}$ and SM were involved in interpretation of data. WM and $\mathrm{RC}$ were involved in manuscript writing and drafting. FV, WM and $\mathrm{RC}$ were involved in revision of the manuscript. WM, RC, MZ, SM and FV were involved in approval of the final version of the manuscript. The document has been reviewed and corrected by a native English speaker with extensive scientific editorial experience to ensure a high level of spelling, grammar and punctuation.

Funding This research received no specific grant from any funding agency in the public, commercial or not-for-profit sectors.

Competing interests None declared.

Provenance and peer review Not commissioned; externally peer reviewed.

Data sharing statement Online supplementary data (results of overdispersion tests, R-script to detect the greatest cut-off for the winsorisation procedure) have been provided as an online supplementary file. Other statistical results are available by emailing walter.mazzucco@unipa.it.

Open Access This is an Open Access article distributed in accordance with the Creative Commons Attribution Non Commercial (CC BY-NC 4.0) license, which permits others to distribute, remix, adapt, build upon this work noncommercially, and license their derivative works on different terms, provided the original work is properly cited and the use is non-commercial. See: http:// creativecommons.org/licenses/by-nc/4.0/

\section{REFERENCES}

1. Summary tables of mortality estimates by cause, age and sex, globally and by region, 2000-2015. In: Estimates for 2000ñ2015 Health statistics and information systems WHO. http://www.who.int/ entity/healthinfo/global_burden_disease/GHE2015_Deaths_Global_ 2000_2015.xls?ua=1 (accessed 22 Mar 2017).

2. Barchitta M, Fragapane S, Quattrocchi A, et al. Environmental health risk communication in the case "Terra dei Fuochi": content analysis of online newspaper articles. Ann Ig 2015;27:30-8.

3. Crocetti E, Pirastu R, Buzzoni C, et al. Results in 3 Rapporto Sentieri. Studio epidemiologico nazionale dei territori e degli insediamenti esposti a rischio da inquinamento. Epidemiol Prev 2014;38(Suppl 1): 29-124.

4. Straif K, Cohen A, Samet J. Air pollution and cancer. IARC Scientific publication no.161. https://www.iarc.fr/en/publications/books/sp161/ AirPollutionandCancer161.pdf (accessed 18 Jan 2016).

5. Agents classified by the IARC monographs, volumes 1-117. In: Monographs on the evaluation of carcinogenic risk to humans. International Agency for Research on Cancer (IARC). http://monographs.iarc.fr/ENG/Classification/ (accessed 22 Mar 2017).

6. Boffetta $P$, Nyberg F. Contribution of environmental factors to cancer risk. Br Med Bull 2003;68:71-94.

7. Allemani $\mathrm{C}$, Weir HK, Carreira $\mathrm{H}$, et al. Global surveillance of cancer survival 1995-2009: analysis of individual data for 25,676,887 patients from 279 population-based registries in 67 countries (CONCORD-2). Lancet 2015;385:977-1010.

8. Alwan A, Armstrong T, Bettcher D, et al. WHO Global Status Report on non-communicable diseases 2010. Geneva, 2011.

9. Melissa G. Health literacy and numeracy. Workshop summary. Washington: The National Academy Press, 2014. http://www.nap. edu/catalog/18660/health-literacy-and-numeracy-workshop-summary (accessed 18 Jan 2016).

10. Reyna VF, Nelson WL, Han PK, et al. How numeracy influences risk comprehension and medical decision making. Psychol Bull 2009;135:943-73.

11. Edwards A, Elwyn G, Mulley A. Explaining risks: turning numerical data into meaningful pictures. BMJ 2002;324:827-30

12. CDC. Updated Guidelines for evaluating Public Health Surveillance Systems. MMWR 2001;50(RR13):1-35. http://www.cdc.gov/mmwr/ preview/mmwrhtml/rr5013a1.htm (accessed 18 Jan 2016).

13. Bray F, Soerjomataram I. The changing global burden of cancer: transitions in human development and implications for cancer prevention and control. In: Gelband H, Jha P, Sankaranarayanan R, Horton S, eds. Cancer: disease control priorities. 3rd edn. Vol 3. Washington DC: The International Bank for Reconstruction and Development/The World Bank, 2015. Chapter 2, pp 23-44.

14. Rapporto sui tumori a Palermo e provincia. Anni 2003-2007. Registro Tumori Palermo e Provincia. Anno 2011. http://www.unipa.it/dipartimenti/ dipartimentodiscienzeperlapromozionedellasaluteematernoinfantileg dalessandro/.content/documenti/Rapporto-sui-tumori-a-Palermo-eProvincia-anni-2003-2007-1.pdf (accessed 18 Jan 2016).

15. Cancer in Friuli Venezia Giulia Incidence, Survival and Prevalence: 1995-2005. Agenzia Regionale della Sanità Friuli Venezia Giulia. http://www.cro.it/opencms/export/sites/cro/it/azienda_informa/_docs/ registro-tumori-1995-2005.pdf (accessed 18 Jan 2016).

16. Jemal A, Vineis P, Bray F, et al. The Cancer Atlas. 2nd edn. Lyon: Non series publications IARC, 2014.

17. Atlante Sanitario della Sicilia. Suppl. monografico Notiziario Dipartimento per le Attività Sanitarie ed Osservatorio Epidemiologico. Assessorato della Salute, Regione Sicilia. Anno 2013. http://pti.regione.sicilia.it/portal/page/portal/PIR_PORTALE/ PIR_LaStrutturaRegionale/PIR_AssessoratoSalute/PIR AreeTematiche/PIR Atlanteoncologico (accessed 18 Jan 2016).

18. Visschers VH, Meertens RM, Passchier WW, et al. Probability information in risk communication: a review of the research literature. Risk Anal 2009;29:267-87.

19. Lipkus IM, Hollands JG. The visual communication of risk. Natl Cancer Inst Monogr 1999;25:149-63.

20. Mclnerny GJ, Chen M, Freeman R, et al. Information visualization for science and policy: engaging users and avoiding bias. Trends Ecol Evol 2014;29:148-57.

21. Mappa dei Registri Tumori di popolazione. Associazione Italiana Registri Tumori (AIRTUM) 2015. http://www.registri-tumori.it/cms/it/ copertura (accessed 18 Jan 2016)

22. Ricostruzione intercensuaria della popolazione 2002-2011. Istituto Nazionale di Statistica. 2015. http://www.demo.istat.it (accessed 18 Jan 2016).

23. Greenland S, Rothman KJ, Lash TL. Measures of effect and measures of association. In: Rothman KJ, Greenland S, Lash TL, eds. Modern epidemiology. 3rd edn. Philadelphia: Lippincott Williams \& Wilkins, 2008:67-9.

24. Mantel N, Stark CR. Computation of indirect-adjusted rates in the presence of confounding. Biometrics 1968;24:997-1005.

25. Morris SE, Wakefield JC. Assessment of disease risk in relation to a pre-specified source. In: Elliot P, Wakefield JC, Best NG, Briggs DJ, eds. Spatial epidemiology: methods and applications. New York: Oxford University Press, 2000:53-184.

26. Spiegelhalter DJ. Funnel plots for institutional comparisons. Qual Saf Health Care 2002;11:390-1.

27. Spiegelhalter DJ. Handling over-dispersion of performance indicators. Qual Saf Health Care 2005;14:347-51

28. Silcocks P. Hazard ratio funnel plots for Survival. J Epidemiol Community Health 2009;63:856-61.

29. Spiegelhalter DJ. Funnel plots for comparing institutional performance. Stat Med 2005;24:1185-202.

30. Confini amministrativi, dei sistemi locali del lavoro e delle NUTS2 in versione generalizzata. Istituto Nazionale di Statistica 2010. http:/ www.istat.it/it/files/2011/04/com2011 g.zip (accessed 18 Jan 2016).

31. Mazumdar S. Shape and scale in detecting disease clustersî. [PhD (Doctor of Philosophy) thesis]. University of lowa, 2008. http://ir. uiowa.edu/etd/208 (accessed 18 Jan 2016).

32. Richards TB, Berkowitz Z, Thomas CC, et al. Choropleth map design for cancer incidence, part 2. Prev Chronic Dis 2010;7:A24.

33. Cromley G, Cromley EK. Choropleth map legend design for visualizing community health disparities. Int $J$ Health Geogr 2009;8:52.

34. Besag J, Newell J. The detection of clusters in rare diseases. Wiley $R$ Stat Soc 1991;154:143-55.

35. Sui DZ, Holt JB. Visualizing and analysing public-health data using value-by-area cartograms: toward a new synthetic framework. Cartographica 2008;43:3-20.

36. Kumar N. Frequency histogram legend in the choropleth map: a substitute to traditional legends. Cartogr Geogr Inform Sci 2004;31:217-36.

37. Quaresma M, Coleman MP, Rachet B. Funnel plots for population-based cancer survival: principles, methods and applications. Stat Med 2014;33:1070-80.

38. Dover DC, Schopflocher DP. Using funnel plot in public health surveillance. Popul Health Metr 2011;9:58

39. Hildon Z, Allwood D, Black N. Impact of format and content of visual display of data on comprehension, choice and preference: a systematic review. Int J Qual Health Care 2012;24:55-64.

40. Rakow T, Wright RJ, Spieghelhalter D, et al. The pros and cons of funnel plots as an aid to risk communication and patient decision making. Br J Psychol 2015;106:327-48.

41. Ocana-Riola R. Common errors in disease mapping. Geospat Health 2010;4:139-54.

42. Hsu CC, Brian A. The Delphi technique: making sense of consensus. Pract Assess Res Eval. Pract Assess Res Eval 2007;12:1-8. 